\title{
Introduction to the special issue on "Subduction Zones"
}

\author{
S. J. H. Buiter ${ }^{1,2}$, F. Funiciello ${ }^{3}$, and J. van Hunen ${ }^{4}$ \\ ${ }^{1}$ Geological Survey of Norway, Geodynamics Team, Leiv Eirikssons vei 39, 7040 Trondheim, Norway \\ ${ }^{2}$ University of Oslo, The Centre for Earth Evolution and Dynamics, 0316 Oslo, Norway \\ ${ }^{3}$ Università Roma Tre, Dipartimento di Scienze, L.go S. Leonardo Murialdo 1, 00146, Rome, Italy \\ ${ }^{4}$ Durham University, Department of Earth Sciences, Durham DH1 3LE, UK \\ Correspondence to: S. J. H. Buiter (susanne.buiter@ngu.no)
}

\section{The subduction process}

The discoveries in the previous century of continental drift, convection in Earth's mantle, and the formation of oceanic lithosphere at mid-ocean ridges set the stage for the realisation that oceanic material is continuously recycled back into the mantle (e.g., Wegener, 1918; Holmes, 1931; Runcorn, 1956; Hess, 1962; Vine and Matthews, 1963; Wilson, 1966). This idea is also confirmed by evidence that no in situ oceanic lithosphere older than ca. 270 Ma exists on Earth (Müller et al., 2008; Fig. 1a). The process of sinking of cold oceanic lithosphere into the mantle, occurring at convergent margins, is called subduction.

Subduction is not only responsible for mixing surface material back to the deep Earth and introducing significant chemical variation back into the mantle (Christensen and Hofmann, 1994), but also for driving plate motions (Forsyth and Ueda, 1975), mountain building and the growth of new continental crust (Davidson and Arculus, 2006). Subduction also deeply modifies the thermal structure of the mantle and accounts for arc volcanism, in addition to causing substantial surface (vertical and horizontal) deformations and releasing most of the seismic energy of the Earth. The subduction process plays, therefore, a key role in the geodynamical and geochemical phenomena that shape our Earth and, for this reason, has led to a more-than-average attention from the Earth Science community. But, despite these efforts, subduction still holds many enigmas and open questions. The most important are embedded in the lack of a common behaviour of global subduction zones (e.g., Uyeda and Kanamori, 1978). Some subduction zones are long-lived, such as the Andes subduction zone, which is over 100 million years old, whereas others have just initiated, such as the New Hebrides and Puysegur subduction zones. Present-day subduction zones are also diverse in terms of trench motion, slab dip, nature of the overriding plate, back-arc tectonic regime, behaviour at the $660 \mathrm{~km}$-discontinuity, seismicity, and volcanic productivity of the arc (e.g., Jarrard, 1986; Pacheco et al., 1993; Heuret and Lallemand, 2005; Acocella and Funiciello, 2009; Heuret et al., 2011; Hayes et al., 2012).

Subduction is a complex dynamic process, which occurs over long timescales and to large depths and integrates smallscale with large-scale phenomena. This process can, therefore, only be understood by adopting a multidisciplinary approach integrating geological observations and geophysical imaging of regions of past and present subduction, with geochemical fingerprinting of materials recycled in the subduction system, and studies of subduction dynamics in space and time. The direct association with devastating earthquakes and active volcanism signifies a social need for an understanding of all aspects of this process. Decades of research have furthered our understanding of the large-scale kinematics of subduction processes and the close links between subducting lithosphere, mantle flow, and surface deformation. However, past research has made it very clear that several fundamental questions remain unanswered. We therefore considered it timely to bring together a selection of papers that highlight the current state of subduction research.

\section{The Subduction Zones special issue}

In this special issue we follow the subducting lithosphere on its journey from the surface to the lower mantle (Fig. 1b). Using tomographic imaging, numerical modelling, and field observations, the contributing articles outline several challenges in the subduction system. In the text below, references to articles in the special issue are in italics.

Subduction zones are associated with thrust earthquakes on the interplate contact and with intermediate-to-deep slab seismicity, posing a serious threat to communities living 

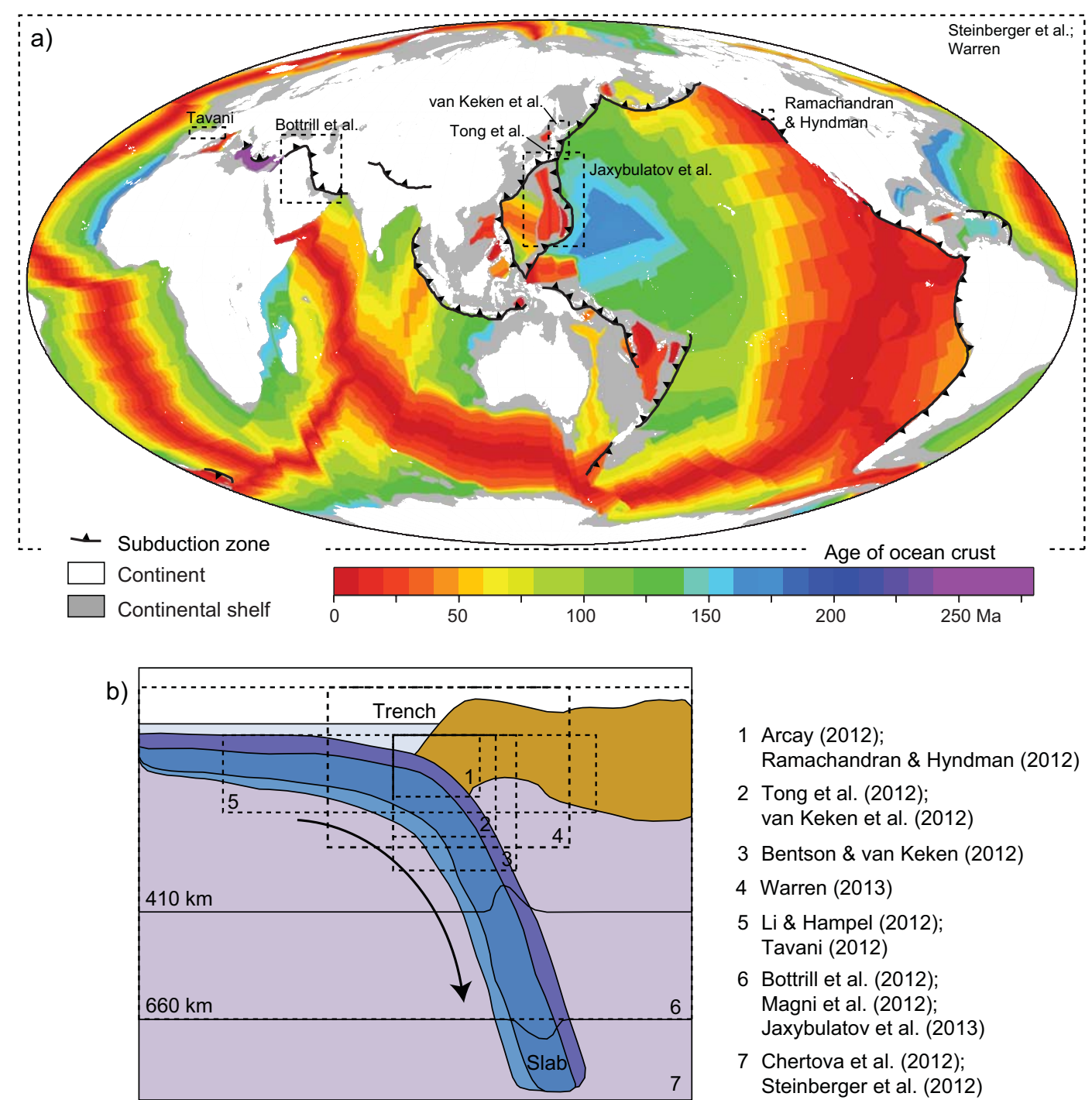

1 Arcay (2012);

Ramachandran \& Hyndman (2012)

2 Tong et al. (2012);

van Keken et al. (2012)

3 Bentson \& van Keken (2012)

4 Warren (2013)

5 Li \& Hampel (2012); Tavani (2012)

6 Bottrill et al. (2012);

Magni et al. (2012);

Jaxybulatov et al. (2013)

7 Chertova et al. (2012);

Steinberger et al. (2012)

Fig. 1. (a) Map of present-day subduction systems, and (b) schematic subduction zone cross-section with areas of study of the Subduction Zones special issue indicated as dashed boxes. Age of ocean crust from Müller et al. (2008).

close to these convergent regions (Fig. 1a). Previous studies have found that faults in the upper part of a subduction zone are susceptible to changes in ice and water loads (e.g., Chochran et al. 2004; Luttrell and Sandwell, 2010). Li and Hampel (2012) use 2-D finite element models to show that glacial-interglacial sea level variations can be responsible for significant stress variations within convergent plates and, in turn, for the earthquake cycle of subduction thrust faults. Earthquakes are promoted during sea-level fall and delayed during sea-level rise. Arcay (2012) finds that subduction interplate dynamics are strongly dependent on both ductile and brittle strength parameters. The evolution of the depth of the brittle-to-ductile transition and the kinematic decoupling depth along the subduction interface are both influenced by the interplate friction coefficient and the mantle wedge strength. When comparing the thermochemical mod- elling results with observations, it suggests a moderate-tostrong viscosity reduction of the asthenosphere due to metasomatism of the mantle wedge.

The thermal structure of a subduction system is important for understanding subduction seismicity, slab dehydration, arc volcanism and geochemistry. Bengtson and van Keken (2012) investigate to which extent the common approach of using 2-D cross-sections provides a reasonable image of the 3-D system. 3-D numerical models of the thermal structure and the flow regime in the mantle wedge show that 2-D crosssections are reasonable for arcs that have minor along-strike variations. However, a full 3-D model is unavoidable to simulate strongly curved subduction systems, such as the Marianas, where significant 3-D mantle flow is induced in the mantle wedge by the subduction process. 
When an oceanic basin closes and continental lithosphere enters a subduction zone, the positive buoyancy of the continental crust will resist subduction, leading to a slow-down, and ultimately to the end of subduction (e.g., McKenzie, 1969). Continental collision is accompanied by severe crustal and lithospheric deformation, mountain building, slab breakoff, metamorphism, and the exhumation of high and ultrahigh pressure [(U)HP] rocks. Warren (2013) reviews mechanisms to subduct continental crust to (U)HP conditions and exhume the rocks back to Earth's surface. The record of exhumation is complicated by the fact that exhumation mechanisms may change in time and space within the same subduction zone. Buoyancy and external tectonic forces drive exhumation, but the changing spatial and temporal dominance of different driving forces still remains unclear and further research is required to determine to what extent exhumation is transitory and discrete versus continuous and long-lived.

Using 2-D numerical models, Magni et al. (2012) show that trenches can start advancing by 40 to $220 \mathrm{~km}$ once continental collision occurs. Locking of the subduction zone and subsequent steepening of the slab induce trench advance. These results highlight that trench advance can be intrinsic to the subduction system and need not necessarily be driven by external plate-driving forces only. The changes in thermal and isostatic forces, flexural strength and mantle-induced stresses that accompany collision are also expressed in vertical surface motions. Bottrill et al. (2012) show that during ongoing subduction a back-arc basin forms and deepens once collision starts due to steepening of the slab. In their 2-D numerical models, this basin is transient as initial surface uplift close to the suture zone migrates into the former basin after slab detachment. The model results fit with the sedimentation record and topography on the overriding plate for the ArabiaEurasia collision zone where a temporary shallow marine basin existed in the Upper Oligocene - Early Miocene. Such temporal and spatial variations in horizontal and vertical surface displacements may further complicate the often already complex interpretation of the geological record of past and present subduction zones.

The Pyrenean orogen formed after inversion of a Mesozoic rift system, resulting in continental collision of the Iberian and Eurasian plates (e.g., Muñoz, 1992). To the west in the Cantabrian domain, the Iberian continental lithosphere subducts underneath the transitional-to-oceanic lithosphere of the Bay of Biscay. Tavani (2012) describes this unusual tectonic setting and suggests that the preserved lithosphericscale syncline structures in the Cantabrian domain form one of the few natural examples of subduction initiation.

The oceanic lithosphere carries fluids (mainly water), which are contained either as free fluid in the pores of the rocks or bound mineralogically (e.g., Rüpke et al., 2004). As the subducted lithosphere reaches higher pressures and temperatures, these fluids are released by compaction and dehydration reactions. Ramachandran and Hyndman (2012) present $\mathrm{P}$ - and $\mathrm{S}$-wave velocities from 3-D seismic tomog- raphy to constrain fluids released from the young and hot Cascadia subducting lithosphere. The seismic velocities indicate substantial amounts of serpentinite in the forearc mantle, lending itself towards weakness, which has important consequences for earthquake potential and collision tectonics. Significant silica deposition at the base of the lower crust makes it a primary contributor to the average composition of the continental crust. The Pacific slab subducting under northeast Japan is an example of a cold subduction system due to the high convergence rate and old age of the subducting lithosphere. Tong et al. (2012) present P- and S-wave seismic tomography that image fluids released from dehydration of the subducting Pacific lithosphere under the 2011 Iwaki earthquake area and Fukushima nuclear power plant location. As fluids decrease fault friction, slab dehydration might have triggered earthquake activity. Based on this study, it is suggested that the Fukushima nuclear power plant site should be strengthened to survive future earthquake activity in the area. The role of fluids in the generation of intermediatedepth $(>40 \mathrm{~km})$ seismicity is investigated by Van Keken et al. (2012) with 2-D numerical models in which slab kinematics is prescribed. They find that intermediate depth seismicity in the upper part of the slab below northern Japan is delimited by the blueschist to hydrous ecologite phase change, which forms a major dehydration front in the subducted crust. The correlation breaks down in the junction between the northern Japan and Kurile arcs where time dependent, 3-D dynamics of the slab may significantly affect the thermal slab structure and hence dehydration reactions.

Jaxybulatov et al. (2013) present P- and S-wave tomography of the mantle beneath the Izu-Bonin and Mariana arcs. The tomographic models show along-strike variations in the subduction system with differences in slab dip angle that correlate with segments that are also delineated by deep seismicity clusters.

Numerical and analogue models of subduction necessarily need to simplify the many complex aspects of subduction in order to be able to arrive at reliable solutions. Among the many problems inherent in this process are choices of deformation mechanisms, values for mechanical and thermal material properties, and the treatment of boundary conditions for models that do not simulate the entire Earth. Chertova et al. (2012) test the influence of sidewall boundary conditions on the dynamics of subduction with regional-scale 2-D numerical models. They document differences in slab evolution, trench motion and mantle flow in models with open sidewalls compared to closed (free-slip) sidewalls and conclude that open boundaries soften the impact of side boundary conditions, allowing for smaller lateral extent of the models. Whole-Earth geodynamic models of mantle flow do not suffer from the necessity of lateral boundary conditions. Steinberger et al. (2012) present a new comparison of wholemantle tomography with viscous geodynamic flow models, which are based on 300 million years of subduction history. The correlation between the tomography and geodynamic 
models is improved in comparison to previous models. One important aspect for this improved fit is the presence of a chemical layer at the base of the lower mantle, shaped into two piles as the Pacific and African Large Low Shear Velocity Provinces.

\section{Concluding remarks: Future directions in subduction research}

A short introduction to a collection of thirteen papers cannot do full justice to the broad and thriving discipline of subduction research. Nevertheless, we would like to conclude by highlighting some avenues of future research that we consider interesting and promising (see also Gerya (2011) for future directions in subduction modelling):

1. Identifying and analysing key-elements for the occurrence of mega-earthquakes that characterise convergent margins and determining the most likely conditions that can trigger such events;

2. Combining observations of young subduction zones and sparse remnants of the initial stages of older subduction zones with dynamic models to evaluate scenarios of subduction initiation, and determine whether a common mechanism of subduction initiation exists;

3. Investigating mechanisms of exhumation of (ultra-)high pressure and temperature rocks, especially with large semi-coherent terranes;

4. Correlating slabs imaged with seismic tomography to subduction histories and linking the evolution of Earth's surface to the dynamics of the deep Earth;

5. Defining the role of structures inherited from previous extensional or convergent deformation phases on the distribution of later deformation;

6. Evaluating controls on the dynamics of the interaction of subducted lithosphere with the $660 \mathrm{~km}$ discontinuity;

7. Close coupling of dynamic models with fluids and melts;

8. A discussion of which laboratory creep laws should be used in numerical subduction models.

A list like this is never complete and invariably coloured by our own research interests and experiences in modelling subduction. However, we hope that our list of future research directions illustrates the many open questions that still surround the subduction process. We have no doubt that many exciting answers will be discovered from multidisciplinary approaches to inter-related aspects of the subduction process operating over a large range of spatial and temporal scales.
Acknowledgements. We would like to thank all authors for submitting their work to the "Subduction Zones" special issue and all reviewers for their feedback on the manuscripts. This special issue was initiated after the session "Subduction zone dynamics from the surface to the lower mantle" at the EGU General Assembly in 2011. We thank Solid Earth Executive Editor Darren Gröcke for reviewing this introduction and both Darren and the Copernicus editorial office for their efforts in making the special issue possible. S.B. acknowledges funding by the Norwegian Research Council (NFR project 180449).

Special Issue: "Subduction zones"

Edited by: S. Buiter, F. Funiciello, and J. van Hunen

\section{References}

Acocella, V. and Funiciello F.: Structural control of arc volcanism and related kinematic setting: an overview, Earth Planet. Sci. Lett., 289, 43-53, 2010.

Arcay, D.: Dynamics of interplate domain in subduction zones: influence of rheological parameters and subducting plate age, Solid Earth, 3, 467-488, doi:10.5194/se-3-467-2012, 2012.

Bengtson, A. K. and van Keken, P. E.: Three-dimensional thermal structure of subduction zones: effects of obliquity and curvature, Solid Earth, 3, 365-373, doi:10.5194/se-3-365-2012, 2012.

Bottrill, A. D., van Hunen, J., and Allen, M. B.: Insight into collision zone dynamics from topography: numerical modelling results and observations, Solid Earth, 3, 387-399, doi:10.5194/se3-387-2012, 2012.

Chertova, M. V., Geenen, T., van den Berg, A., and Spakman, W.: Using open sidewalls for modelling self-consistent lithosphere subduction dynamics, Solid Earth, 3, 313-326, doi:10.5194/se3-313-2012, 2012.

Christensen, U. and Hofmann, A. W.: Segregation of subducted oceanic crust in the convecting mantle, J. Geophys. Res., 99, 19867-19884, 1994.

Cochran, E. S., Vidale, J. E., and Tanaka, S.: Earth tides can trigger shallow thrust fault earthquakes, Science, 306, 1164-1166, 2004.

Davidson, J. P. and Arculus, R. J.: The significance of Phanerozoic arc magmatism in generating continental crust, in: Evolution and Differentiation of the Continental Crust, edited by: Brown, M. and Rushmer, T., Cambridge University Press, 135-172, 2006.

Forsyth, D. W. and Uyeda, S.: On the relative importance of driving forces of plate motions, Geophys. J. R. Astro. Soc., 43, 163-200, 1975.

Gerya, T.: Future directions in subduction modelling, J. Geodyn., 52, 344-378, doi:10.1016/j.jog.2011.06.005, 2011.

Hayes, G. P, Wald, D. J., and Johnson, R. L.: Slab 1.0: A Threedimensional model of global subduction zone geometries, J. Geophys. Res., 117, B01302, doi:10.1029/2011JB008524, 2012.

Hess, H. H.: History of ocean basins, in: Petrologic studies, edited by: Engle, E. A. J., Geol. Soc. Am., New York, 1962.

Heuret, A. and Lallemand, S.: Plate motions, slab dynamics and back-arc deformation, Phys. Earth Planet. In., 149, 31-51, 2005.

Heuret, A., Lallemand, S., Funiciello, F., Piromallo, C., and Faccenna, C.: Physical characteristics of subduction interface type seismogenic zones revisited, G-cubed, 12, Q01004, doi:10.1029/2010GC003230, 2011. 
Holmes, A.: Radioactivity and Earth movements, Transactions of the Geological Society of Glasgow, 18, 559-606, 1931.

Jarrard, R. D.: Relations among subduction parameters, Rev. Geophys., 24, 217-284, 1986.

Jaxybulatov, K., Koulakov, I., and Dobretsov, N. L.: Segmentation of the Izu-Bonin and Mariana slabs based on the analysis of the Benioff seismicity distribution and regional tomography results, Solid Earth, 4, 59-73, doi:10.5194/se-4-59-2013, 2013.

Li, T. and Hampel, A.: Effect of glacial-interglacial sea-level changes on the displacement and stress field in the forearc and along the plate interface of subduction zones, Solid Earth, 3, 6370, doi:10.5194/se-3-63-2012, 2012.

Luttrell, K. and Sandwell, D.: Ocean loading effects on stress at near shore plate boundary fault systems, J. Geophys. Res., 115, B08411, doi:10.1029/2009JB006541, 2010.

Magni, V., van Hunen, J., Funiciello, F., and Faccenna, C.: Numerical models of slab migration in continental collision zones, Solid Earth, 3, 293-306, doi:10.5194/se-3-293-2012, 2012.

McKenzie, D. P.: Speculations on the Consequences and Causes of Plate Motions, Geophys. J. R. Astr. Soc., 18, 1-32, 1969.

Muñoz, J. A.: Evolution of a continental collision belt: ECORSPyrenees crustal balanced section, in: Thrust Tectonics, edited by: McClay, K. R., 235-246, Chapman and Hall, London, 1992.

Müller, R. D., Sdrolias, M., Gaina, C., and Roest, W. R.: Age, spreading rates, and spreading asymmetry of the world's ocean crust, Geochem. Geophys. Geosyst., 9, Q04006, doi:10.1029/2007GC001743, 2008.

Pacheco, J. F., Sykes, L. R., and Scholz, C. H.: Nature of Seismic Coupling Along Simple Plate Boundaries of the Subduction Type, J. Geophys. Res., 98, 14133-14159, 1993.

Ramachandran, K. and Hyndman, R. D.: The fate of fluids released from subducting slab in northern Cascadia, Solid Earth, 3, 121129, doi:10.5194/se-3-121-2012, 2012.
Runcorn, S. K.: Palaeomagnetic comparisons between Europe and North America, P. Geol. Assoc. Can., 8, 77-85, 1956

Rüpke, L. H., Phipps Morgan, J., Hort, M., and Connolly, J. A. D.: Serpentine and the subduction zone water cycle, Earth Planet. Sci. Lett., 223, 17-34, doi:10.1016/j.epsl.2004.04.018, 2004.

Steinberger, B., Torsvik, T. H., and Becker, T. W.: Subduction to the lower mantle - a comparison between geodynamic and tomographic models, Solid Earth, 3, 415-432, doi:10.5194/se-3415-2012, 2012.

Tavani, S.: Plate kinematics in the Cantabrian domain of the Pyrenean orogen, Solid Earth, 3, 265-292, doi:10.5194/se-3-2652012, 2012.

Tong, P., Zhao, D., and Yang, D.: Tomography of the 2011 Iwaki earthquake (M 7.0) and Fukushima nuclear power plant area, Solid Earth, 3, 43-51, doi:10.5194/se-3-43-2012, 2012.

Uyeda S. and Kanamori, H.: Back-arc opening and the Mode of Subduction, J. Geophys. Res., 34, 1049-1061, 1979.

van Keken, P. E., Kita, S., and Nakajima, J.: Thermal structure and intermediate-depth seismicity in the Tohoku-Hokkaido subduction zones, Solid Earth, 3, 355-364, doi:10.5194/se-3-355-2012, 2012.

Vine, F. J. and Matthews, D. H.: Magnetic anomalies over oceanic ridges, Nature, 199, 947-949, 1963.

Warren, C. J.: Exhumation of (ultra-)high-pressure terranes: concepts and mechanisms, Solid Earth, 4, 75-92, doi:10.5194/se-475-2013, 2013.

Wegener, A.: Die Entstehung der Kontinente und Ozeane, Vieweg, Brunswick, 1915.

Wilson, J. T.: Did the Atlantic close and then reopen?, Nature, 211, 676-681, 1966. 